\title{
Dental students work with inner city kids
}

Dental students from Plymouth University have been working with an inner city children's nursery run by Barnardo's in order to look at the issues affecting children's oral health in urban areas.

The students worked with children, parents and staff at Nomony Children's Centre

(Barnardo's) in Plymouth. They ran a fun and engaging interactive show for the children with puppets and music, to highlight the main aspects of effective tooth brushing. They then worked with the children in groups to talk them through the process of teeth cleaning while they practised on their own teeth. At the end of the session the children were left with a range of resources, including toothbrushes and toothpaste, so that they could carry on with their daily brushing.

Another element of the project was attendance at a Barnardo's community support event for parents with young children. There, the dental students ran a stall and talked to visitors about oral hygiene and how to care for their children's teeth, so that as new parents they came away with information and resources to help keep their youngsters' teeth and gums healthy. Around 89 families attended.

The project is part of the Inter Professional Engagement programme which sees dental students undertake a number of projects in the community designed to raise oral health awareness and to improve access to

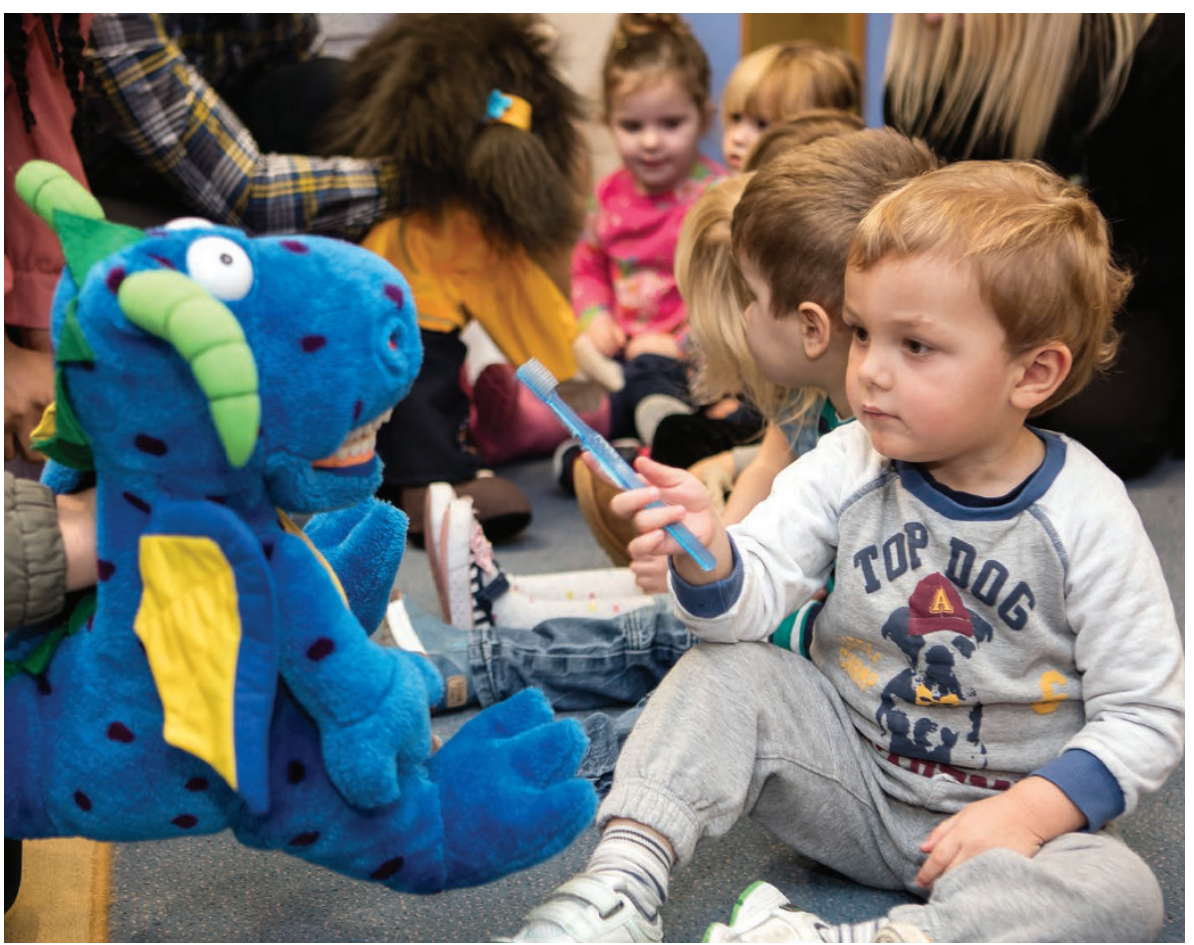

dental care. The programme is delivered by the Community Engagement Team at the Peninsula Dental Social Enterprise.

The project is timely, given that the state of children's teeth in the UK has featured heavily in the media.

Sarah Trubody, Cluster Manager from Nomony Children's Centre, said: 'This is the first time that we have worked with dental students from Plymouth University and it has been a great experience for all concerned. Many parents see the news and are anxious about the health of their children's teeth, but often advice is contradictory or hard to put into practice. The students have been great at getting the children enthused about cleaning their teeth while at the same time providing useful and relevant support to their parents.'

\section{Obesity can affect the oral tissues}

A study of young people undergoing orthodontic treatment has advanced knowledge of the impact of obesity on oral tissues.

It is now recognised that obesity represents a state of chronic subclinical inflammation mediated through the presence of excess adipose tissue. In this investigation, the consequences of obesity for orthodontic tooth movement have been investigated.

Led by Professor Martyn Cobourne and Dr Guy Carpenter at King's College London Dental Institute, the study involved two cohorts of young people with an average age of 15 years. One group was of normal weight and the other was classified as obese based upon body mass index (BMI).
Taking samples of both saliva and gingival crevicular fluid, the researchers found that the obese young people had significantly increased inflammatory biomarkers in their periodontal tissues prior to treatment. This was associated with a significantly increased initial displacement of the teeth during the first week of treatment and a significantly increased rate of tooth movement over the alignment phase.

The British Orthodontic Society's (BOS') Director of External Relations, Richard George, commented that: 'This study provides evidence that increased BMI can have manifestations for orthodontic patients. Significantly, the patients with obesity had a pre-existing pro-inflammatory state in their periodontal tissues and this influenced how the teeth moved with fixed braces.'

Orthodontic tooth movement is mediated by an inflammatory response within the periodontal tissues following the application of orthodontic force. If obesity can affect how teeth respond to fixed braces, it might also potentially influence root resorption and long-term stability.

The two groups of patients in the study are still in treatment and the research team at King's are currently following them up to the completion of treatment.

Saloom H F, Papageorgiou S N, Carpenter G H, Cobourne M T. Impact of obesity on orthodontic tooth movement in adolescents. J Dent Res 2017; 22034516688448. doi: $10.1177 / 0022034516688448$. [Epub ahead of print]. 